\title{
Meningkatkan Kesejahteraan Masyarakat melalui Membangun Mental Kewirausahaan Istri Petani Tambak yang Tergabung dalam Organisasi PKK Desa Paci Kecamatan Glagah Kabupaten Lamongan
}

\author{
Eka Srirahayu Ariestiningsih"1), Dwi Faqihatus Syarifah Has²) \\ 1), 2) Program Studi Gizi Fakultas Kesehatan Universitas Muhammadiyah Gresik \\ ${ }^{1)}$ eka.ariesty@umg.ac.id, ${ }^{2)}$ dwi syarifah@umg.ac.id
}

\begin{abstract}
ABSTRAK
Kegiatan pengabdian kepada masyarakat ini mengupayakan pemecahan permasalahan kemandirian masyarakat dalam mengolah hasil pangan lokal yang dapat bernilai ekonomi. Kegiatan ini juga mendukung upaya peningkatan pendapatan keluarga yang selanjutnya akan berdampak pada peningkatan kesejahteraan keluarga melalui pendekatan pemberdayaan. Pemberdayaan perempuan dilakukan dengan cara membentuk dan mengembangkan jiwa kewirausahaan pada ibu-ibu yang tergabung dalam organisasi dan kegiatan PKK. Diantara kegiatan yang dilakukan adalah : memberikan motivasi kepada ibu-ibu PKK untuk agar memiliki jiwa berwirausaha, memberikan keterampilan untuk membuat rancangan bisnis dan pembentukkan Kelompok Usaha Mikro Kecil dan Menegah (UMKM), serta mengembangkan produk unggulan desa dengan mengolah bahan pangan lokal yang diharapkan bisa menambah penghasilan untuk keluarga. Jiwa kewirausahaan yang dimiliki oleh ibu-ibu PKK akan mengubah pola pikir sehingga dapat berkreatifitas dan berinovasi untuk menghasilkan produk yang lebih bernilai, yakni Sosis dan Nugget Bandeng. Bahan dasar pembuatan sosis dan nugget adalah bandeng yang biasa dijual pada pengepul dengan harga rendah karena kualitasnya paling rendah. Metode yang digunakan adalah ceramah, diskusi dan demonstrasi pengolahan produk Sosis dan Nugget dari ikan Bandeng. Luarannya adalah tumbuh berkembangnya jiwa kewirausahaan pada ibu-ibu PKK Dusun Pasi dan Dusun Pelesan, memberikan penghasilan tambahan kepada keluarga dan peningkatan nilai gizi pangan masyarakat, meningkatnya kemampuan membuat rancangan bisnis dalam rangka mewujudkan kegiatan kewirausahaan, terbentuknya Kelompok Usaha Mikro Kecil Menengah (UMKM) PKK; memiliki kemampuan dan keterampilan mengolah bahan pangan local, ibu-ibu PKK Desa Pasi mampu membuat strategi pemasaran produk.
\end{abstract}

Kata-kata kunci: Potensi Desa, Jiwa Kewirausahaan, Pembinaan, Kesejahteraan Keluarga

\begin{abstract}
This community service activities will strive to solve the problem of community independence in processing local food products that can be of economic value. This activity also supports efforts to increase family income which in turn will have an impact on improving family welfare through the empowerment approach. Empowering women is done by forming and developing an entrepreneurial spirit among mothers who are members of the womens organization and activities. Among the activities carried out are: providing motivation to womens organization mothers to have an entrepreneurial spirit, providing skills to make business designs and the formation of Micro and Medium Enterprises (MSMEs), and developing village superior products by processing local food that is expected to increase income for the family. The entrepreneurial spirit of the womens organization will change their mindset so that they can be creative and innovate to produce more valuable products, namely Sausages and Milkfish Nuggets. The basic ingredients for making sausages and nuggets are milkfish which are usually sold to collectors at a low price because of the lowest quality. The method used is a lecture, discussion and demonstration of Sausage and Nugget product processing from milk fish. The outputs that are expected to be realized from this activity are realize of entrepreneurial spirit among womens organization Dusun Pasi and Pelesan hamlets, providing additional income to the family and increasing the nutritional value in Pasi; ability to make business designs in order to realize entrepreneurial activities; establishment of women organization Micro, Small and Medium
\end{abstract}


Enterprises (MSMEs); having the ability and skills to process local food ingredients; women organization in Pasi are able to make product marketing strategies.

Keywords: Village Potential, Entrepreneurship Spirit, Coaching, Family Welfare

\section{PENDAHULUAN}

Desa Pasi dengan luas 380 ha, yang terdiri dari daratan seluas 200 ha dan tambak seluas 150 ha serta perkebunan seluas 30 ha, Desa Pasi adalah desa yang tergenang banjir pada musim hujan karena hampir 50\% wilayah berupa tambak. Hasil tambak Desa Pasi adalah ikan bandeng yang dipanen setiap 5 (lima) bulan sekali, dengan hasil panen sebesar $500 \mathrm{~kg}-1 \mathrm{kwintal}$ per ha. Desa Pasi sangat minim persediaan air bersih, sehingga masyarakat membeli air untuk kepentingan masak dan minum, sedangkan keperluan lain-lain diambil dari sumur yang kebanyakan rasanya asin dan airnya kurang jernih. Terdapat 2 Sekolah Dasar di Desa Pasi yaitu, Sekolah Dasar Negeri Pasi I dan Sekolah Dasar Negeri Pasi II. Warga masyarakat memeriksakan kesehatan di Puskesmas yang berada di wilayah Kecamatan Glagah dan berjarak 1 (satu) Km dari Desa Pasi.

Mata pencaharian Penduduk Desa Pasi mayoritas adalah petani tambak, yakni sebanyak 47\%. 67\% ibu-ibu di Desa Pasi adalah ibu rumah tangga yang tidak berpenghasilan. Dalam keluarga rata-rata memiliki anggota sebanyak 4 (empat) orang, dan rerata penghasilan keluarga sudah sesuai dengan UMR Kabupaten Lamongan. Namun demikian apabila istri mampu memberikan tambahan pendapatan bagi keluarga maka diharapkan bisa meningkatkan kesejahteraan keluarga tersebut.

Upaya penambahan pendapatan keluarga diharapkan bisa meningkatkan kesejahteraan masyarakat melalui pemberdayaan perempuan. Terdapat beberapa kegiatan pemberdayaan perempuan diantaranya adalah pemberdayaan dalam bidang pendidikan dan pelatihan, yang memungkinkan kaum perempuan bisa berpikir rasional dan mampu menghasilkan ide-ide cemerlang yang bisa diterapkan sebagai kegiatan nyata di masyarakat. Kegiatan nyata tersebut harus "laku jual" sehingga menghasilkan nilai tambah untuk kehidupan yang lebih sejahtera (Suyono, 2008).

Untuk meningkatkan pendapatan keluarga diperlukan upaya memberikan kesempatan yang setara kepada penduduk laki-laki dan perempuan dalam memenuhi kebutuhan keluarganya. Salah satu caranya adalah dengan lebih memberdayakan kaum perempuan agar ikut serta dan diperhitungkan dalam lapangan pekerjaan yang mampu menghasilkan keuntungan, sehingga pada akhirnya dapat membantu menopang pemenuhan kebutuhan hidup seluruh keluarga (Suyono, 2008). 
Peningkatan kesejahteraan melalui pemberdayaan perempuan, akan dilakukan dengan menggunakan jejaring organisasi ibu-ibu PKK (Pemberdayaan Kesejahteraan Keluarga). Dimana selain jejaring organisasi PKK terorganisir secara baik juga kegiatannya sudah melembaga dan menjadi bagian dari kehidupan masyarakat Desa Pasi. Aktivitas kegiatan ibu-ibu PKK di Desa Pasi pada umumnya lebih banyak terkonsentrasi pada tingkat Rukun Tetangga (RT), Dusun atau Rukun Warga (RW). Karena pada kedua organisasi masyarakat tersebut kegiatan PKK dirasakan langsung oleh warga Desa Pasi. Dari ke enam Dusun yang ada di Desa Pasi, pada Dusun Pelesan dan Dusun Pasi yang merupakan wilayah yang paling dekat dengan pusat Pemerintahan Desa Pasi dan penghasil bandeng paling banyak.

Sesuai dengan hasil analisis situasi di Deas Pasi, belum berkembangnya kegiatan kewirausahaan pada kalangan ibu-ibu PKK bukan semata disebabkan ketidakmauan untuk memanfaatkan bandeng untuk produk baru, namun karena : (1) Belum dimilikinya jiwa kewirausahaan secara teori oleh Ibu-Ibu PKK Desa Pasi, sehingga tidak memanfaatkan bahan pangan lokal untuk menjadi produk baru, (2) Belum adanya unit kegiatan secara ekonomis yang akan digunakan sebagai wahana Kegiatan Usaha Mikro Kecil Menengah (UMKM), (3) Belum dimilikinya keterampilan pengolahan bahan pangan lokal yang diharapkan mampu memberikan nilai lebih, dan (4) Belum dimilikinya pengetahuan dan keterampilan tentang manajemen usaha dan strategi memasarkan produk baru dari bandeng.

Tujuan kegiatan pengabdian masyarakat ini adalah ibu-ibu PKK Desa Pasi mempunyai jiwa berwirausaha dengan memanfaatkan bahan pangan lokal, yakni bandeng yang merupakan hasil tambak Desa Pasi, sehingga Ibu-ibu PKK Desa Pasi bisa berkegiatan secara ekonomi. Adanya kemampuan berwirausaha bagi ibu-ibu PKK yang tidak bekerja dengan memanfaatkan bandeng kualitas 3 diolah menjadi sosis dan nugget setidakanya akan menambah penghasilan berikut dengan nilai Gizi pangan masyarakat. Berikut adalah tujuan kegiatan (1) Tumbuh berkembangnya kewirausahaan pada ibu-ibu PKK Dusun Pasi dan Dusun Pelesan (2) memberikan penghasilan tambahan kepada keluarga; (3) Kemampuan membuat rancangan bisnis dalam rangka mewujudkan kegiatan kewirausahaan; (4) Terbentuknya Kelompok Usaha Mikro Kecil Menengah (UMKM) PKK; (5) Memiliki kemampuan dan keterampilan mengolah bahan pangan lokal; (6) ibu-ibu PKK Desa Pasi mampu membuat strategi pemasaran produk. 
Tahapan kegiatan pengabdian masyarakat Ibu ibu PKK Desa Pasi adalah : (1) Pemberian motivasi dan penumbuhan jiwa kewirausahaan agar memiliki kreativitas dan berinovasi untuk memproduksi sesuatu agar lebih bernilai dengan memanfaatkan bahan pangan local, (2) Memberikan pelatihan menyusun Rencana Bisnis (Bussiness Plan), (3) Memberikan pembinaan membentuk organisasi sebagai wahana Kegiatan Usaha Mikro Kecil Menengah (UMKM), (4) Mensosialisasikan produk makanan dari bahan bandeng, dari segi nilai ekonomis dan gizi, (5) Memberikan pelatihan pengolahan bandeng menjadi sosis bandeng dan Pendampingan memproduksi sosis bandeng, serta (6) Memberikan pelatihan manajemen usaha dan strategi pemasaran dan Memberikan pelatihan membuat website sederhana untuk penjualan Online.

\section{METODE PENGABDIAN MASYARAKAT}

\subsection{Rancangan Kegiatan Pengabdian Masyarakat}

Pengabdian masyarakat ini dikembangkan dengan pendekatan ilmiah melalui proses deduktif. Rangkaian dari pendekatan ilmiah tersebut adalah mengidentifikasi permasalahan, menentukan tujuan dan manfaat dan merancang prosedur pengabdian masyarakat, melakukan analisis terhadap data dan informasi, serta menjelaskan data dan menarik kesimpulan. Diagram rancangan kegiatan disajikan pada Gambar 1. 


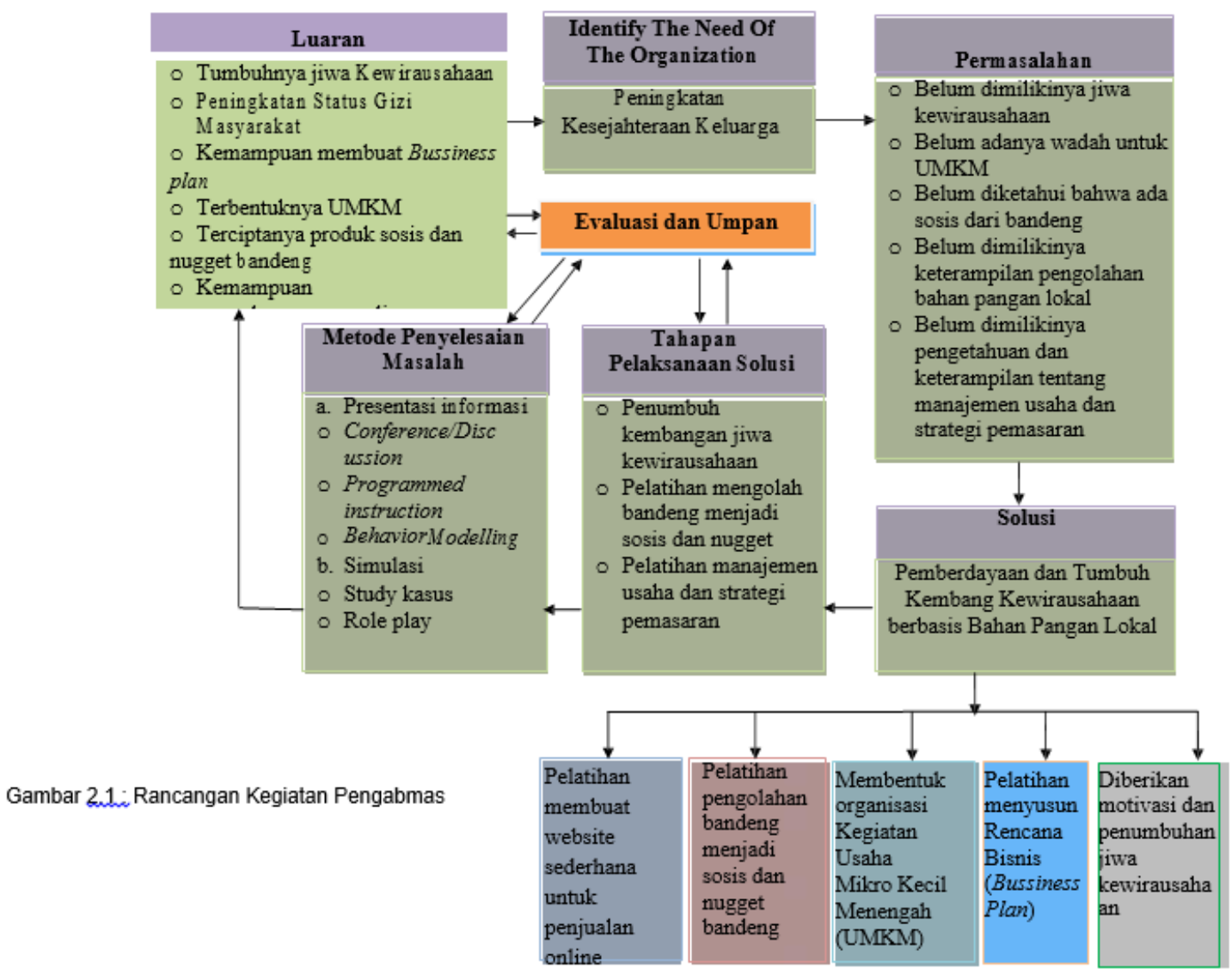

\subsection{Lokasi dan Partisipan Kegiatan Pengabdian Masyarakat}

Lokasi pengabdian masyarakat adalah di Desa Pasi Kecamatan Glagah Lamongan. Dipilihnya Desa Pasi, karena Desa Pasi adalah salah satu desa yang memiliki hasil panen ikan bandeng dalam jumlah besar di Kecamatan Glagah Lamongan. Partisipan Kegiatan adalah Ibu-ibu PKK Dusun Pelesan adalah salah satu Dusun yang dekat dengan Desa Pasi yang terdiri dari 2 (dua) Rukun Tetangga (RT) dan Ibu-ibu PKK Dusun Pasi adalah desa yang berada dipusat Pemerintahan Desa Pasi, yang terdiri dari 2 (dua) Rukun Tetangga (RT).

\subsection{Bahan dan Alat Pengabdian Masyarakat}

a. Bahan yang digunakan adalah : Ikan Bandeng kualitas 3 yang laku murah dipasaran, wortel, Tepung dan bumbu lainnya

b. Tester produk pangan : Nugget Bandeng, Sosis Bandeng

c. Alat yang digunakan untuk penyuluhan : Leaflet, Buku Panduan, Buku Resep, Video pembuatan produk pangan dan LCD

d. Leaflet dan buku panduan : penumbuhan jwa kewirausahaan, menyusun rencana bisnis (Bussines Plan), Pengolahan dan produksi bandeng menjadi nugget dan 
sosis bandeng, serta manajemen usaha dan strategi pemasaran secara sederhana dengan membuat website sederhana untuk penjualan online.

e. Media yang digunakan untuk penyuluhan : Laptop, LCD dan PPT

f. Data: Data Primer didapatkan dari penyebaran kuesioner dan Wawancara terkait kegiatan Pengabdian Masyarakat. Data sekunder, diantaranya : Luas Wilayah, Batas Geografis, Mata pencaharian masyarakat dan pendidikan didapatkan dari Buku Profil Desa Pasi.

\subsection{Metode Pelaksanaan Kegiatan Pengabdian Masyarakat}

Adapun langkah-langkah yang digunakan dalam menyelesaikan persoalan Masyarakat tersebut yakni : Kepada para anggota PKK akan diberikan pendampingan dan pembinaan (pelatihan dan keterampilan):

\section{a. Penumbuhan jiwa Kewirausahaan (entrepreneur)}

Secara rinci kegiatannya adalah sebagai berikut :

1) Mensosialisasikan jiwa kewirausahaan kepada Ibu-Ibu PKK Desa Pasi

2) Meningkatkan pengetahuan tentang kewirausahaan kepada Ibu-lbu PKK Desa Pasi

3) Memotivasi dan memantabkan Ibu-lbu PKK Desa Pasi akan pengolahan bandeng menjadi sosis akan bernilai ekonomi lebih

4) Pelatihan membuat perencanaan bisnis (Business Plan)

5) Membentuk organisasi bisnis sebagai wadah UMKM

b. Pendampingan dan pelatihan keterampilan membuat olahan bandeng yang tidak lolos sortir menjadi sosis dan nugget.

Pelatihan ini untuk menumbuhkan kemampuan ibu ibu PKK untuk memproduksi makanan olahan sebagai kebutuhan sendiri, dan sekaligus dapat dipasarkan kepada masyarakat luas yang diarahkan untuk dapat membantu menambah penghasilan keluarga:

1) Menjadikan bandeng sebagai bahan pangan lokal yang akan diolah sebagai produk baru;

2) Melaksanakan pelatihan mengolah bandeng menjadi sosis dan nugget bandeng 


\section{c. Pelatihan manajemen usaha dan strategi pemasaran}

Pelatihan manajemen usaha adalah pelatihan dan pemberian motivasi dan skill manajerial kewirausahaan, diarahkan untuk menumbuhkan motivasi peserta untuk berwirausaha dan kemampuan mengelola usaha, yang meliputi: (a) Manajemen operasi dan produksi; (b) Manajemen pemasaran; (c) Manajemen keuangan dan akuntansi sederhana (d) Pelatihan pemanfaatan TIK untuk pemasaran.

Pelatihan ini diarahkan untuk menumbuhkan pengetahuan dan pemahaman tentang pemasaran dengan menggunakan TIK, yang mencakup:

1) Pengenalan TIK, dan jejaring media sosial internet

2) Pembuatan blog

3) Pemanfaatan TIK untuk pemasaran secara on line

4) Transaksi dalam pemasaran on line

d. Pendampingan kepada para peserta pelatihan, dalam rangka:

1) Pemahaman dan aplikasi pengetahuan dan skil manajerial

2) Analisis potensi pasar dan pembuatan perencanaan usaha dan agar aplikatif

3) Merancang/membangun dan mengelola usaha bersama dalam bentuk UMKM melalui kegiatan PKK (mulai dari perencanaan, proses produksi, pemasaran, pengaturan mekanisme dan sistem pembagian keuntungan usaha)

\subsection{Pengolahan dan Analisis Data}

Pengolahan data dengan menggunakan Data primer (Profil Desa Pasi) dan Data sekunder (kuesioner hasil kegiatan) diolah dengan menggunakan program excel. Dalam analisis data pengabdian lapangan akan di dukung oleh data kuantitatif dan kualitatif, untuk mengontrol informasi yang bersifat kualitatif diperlukan informasi data kuantitatif sedangkan untuk memperjelas data kuantitatif diperlukan data kualitatif.

\section{HASIL DAN PEMBAHASAN}

Kegiatan pengabdian masyarakat kepada Ibu-ibu PKK Desa Pasi Kecamatan Glagah Lamongan telah dilaksanakan dengan melibatkan tokoh masyarakat dan Dinas terkait. Hasil kegiatan dijelaskan di bagian berikut. 


\subsection{Tumbuhnya Jiwa Kewirausahaan Ibu-Ibu PKK Desa Pasi}

Ibu Ibu PKK Desa Pasi diberikan pelatihan dan motivasi untuk menumbuhkan jiwa kewirausahaan agar memiliki kreativitas dan berinovasi untuk memproduksi sesuatu agar lebih bernilai dengan memanfaatkan bahan pangan local (Gambar 2).

Keberhasilan pemberian motivasi untuk menumbuhkan jiwa wirausaha ibu ibu PKK Desa Pasi dapat dilihat dari:

a. Jumlah ibu ibu PKK Desa Pasi yang hadir untuk mengikuti kegiatan pelatihan hingga program selesai semakin lama semakin banyak

b. Keikutsertaan ibu ibu PKK Desa Pasi untuk menjual produk olahan bandeng secara langsung dan online serta

c. Bertambahnya pengetahuan tentang kewirausahaan ibu ibu PKK Desa Pasi dan komitmen untuk mendapatkan penghasilan secara mandiri, dibuktikan dengan pengisian kuesioner pertanyaan tentang kewirausahaan setelah kegiatan pengabdian masyarakat ini berlangsung.

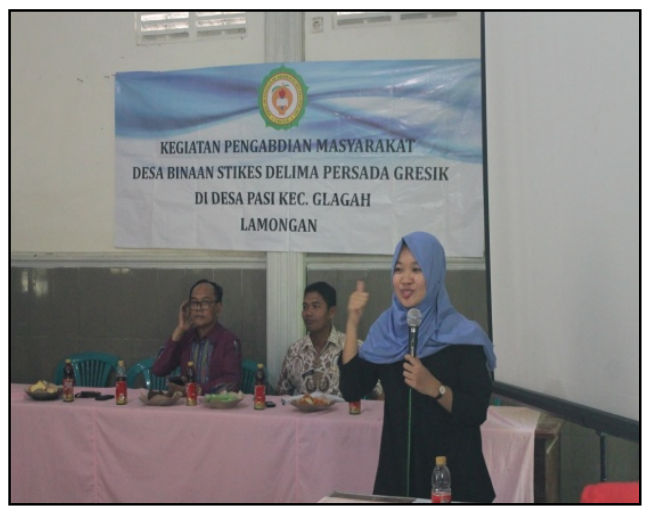

Gambar 2. Pelatihan

3.2. Kemampuan memproduksi makanan olahan untuk kebutuhan sendiri serta dipasarkan kepada masyarakat luas yang diarahkan untuk dapat membantu menambah penghasilan keluarga

Ibu-ibu PKK Desa Pasi dapat memproduksi makanan olahan yang berasal dari bandeng. Produk tersebut dapat dikonsumsi sendiri dengan berbagai variasi olahan bergizi baik berupa nugget maupun sosis. Selain itu Ibu-ibu PKK Desa Pasi juga memproduksi secara massal yakni untuk dipasarkan ke masyarakat secara luas untuk menambah penghasilan keluarga. 


\subsection{Kemampuan Ibu Ibu PKK Desa Pasi untuk Membuat Bussines Plan}

Ibu Ibu PKK Desa Pasi juga diberikan pelatihan untuk membuat bussines plan, sehingga dapat mengatur perencanaan keuangan (permodalan) hingga menghitung laba atau keuntungan yang mereka dapatkan dari penjualan produk mereka (Gambar 3). Ibu Ibu PKK Desa Pasi juga diajarkan cara membuat pembukuan akuntansi secara sederhana dan perekapan keuntungan pada setiap harinya.

Bussines plan, digunakan ibu ibu PKK desa Pasi sebagai proposal untuk membuat koperasi UMKM yang terletak di Balai Desa atau trumah warga untuk menjual produk produk olahan ikan bandeng yakni nugget bandeng dan sosis. Selain itu, ibu ibu PKK Desa Pasi juga merencakanan untuk membuat varian varian baru pada nugget dan sosis bandengnya, tidak hanya rasa original.

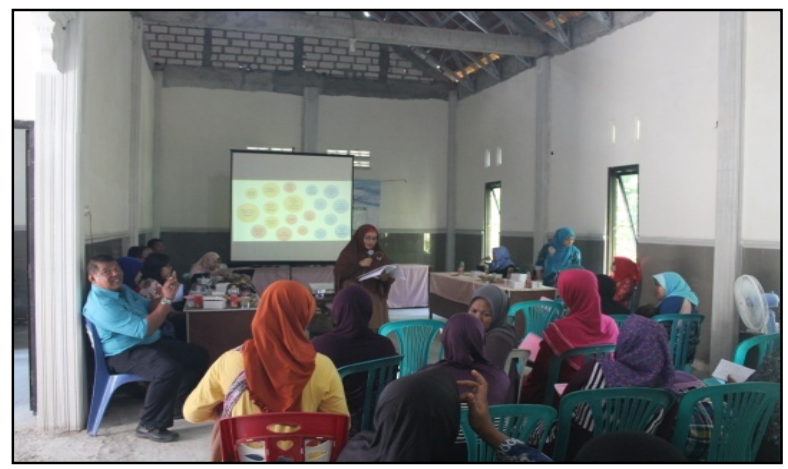

Gambar 3. Pelatihan Pembuatan Bussines Plan

\subsection{Terbentuknya Organisasi sebagai Wahana UMKM}

Adanya komitmen yang tinggi dari Ibu Ibu PKK Desa Pasi untuk berwirausaha menghasilkan terbentuknya UMKM "Pasi Berinovasi" yang dibina dan dijalankan secara mandiri oleh ibu ibu PKK Desa Pasi dengan dibantu oleh Balitbangda Kabupaten Lamongan (Gambar 4).

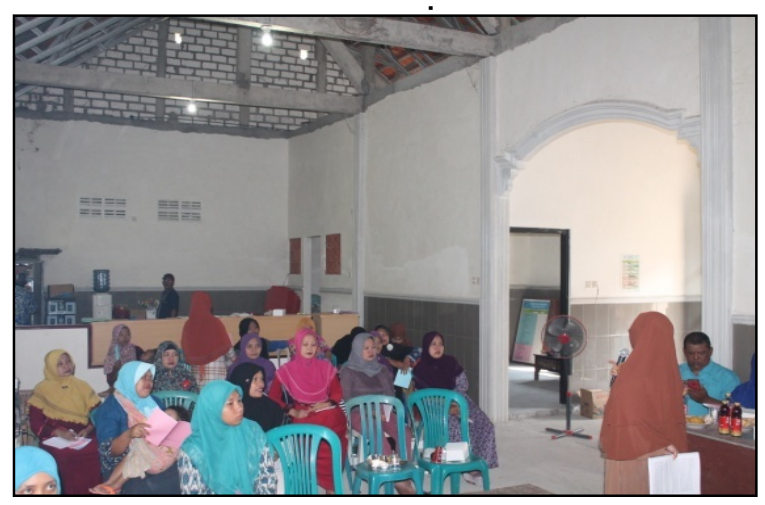


3.5. Terciptanya produk olahan hasil tambak yaitu bandeng menjadi sosis sebagai hasil produksi ibu-ibu PKK Ibu-lbu PKK Desa Pasi yang layak dipasarkan

Produk yang dihasilkan adalah sosis dan nugget bandeng (Gambar 5 dan 6)

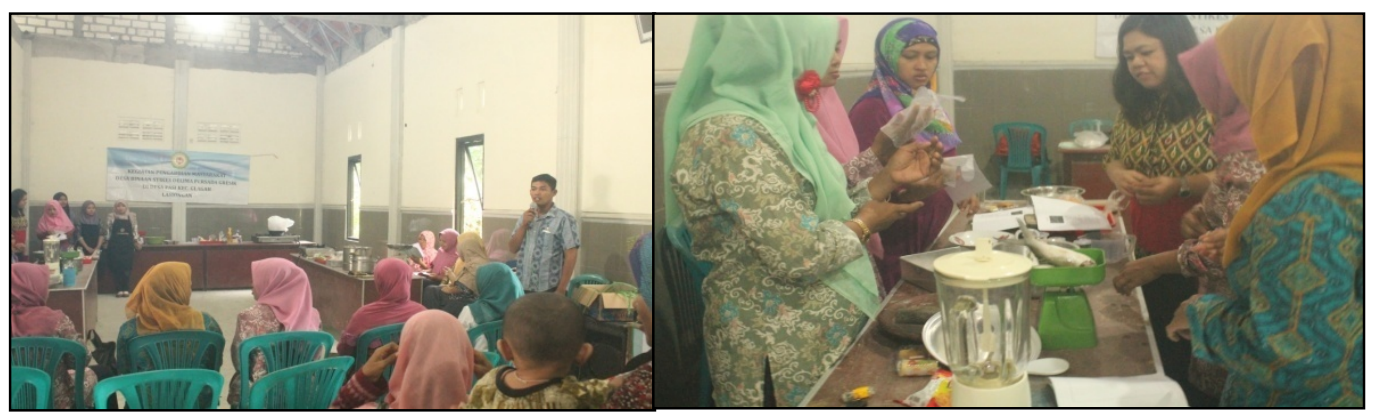

Gambar 5. Proses Pembuatan Sosis dan Nugget dari Ikan Bandeng

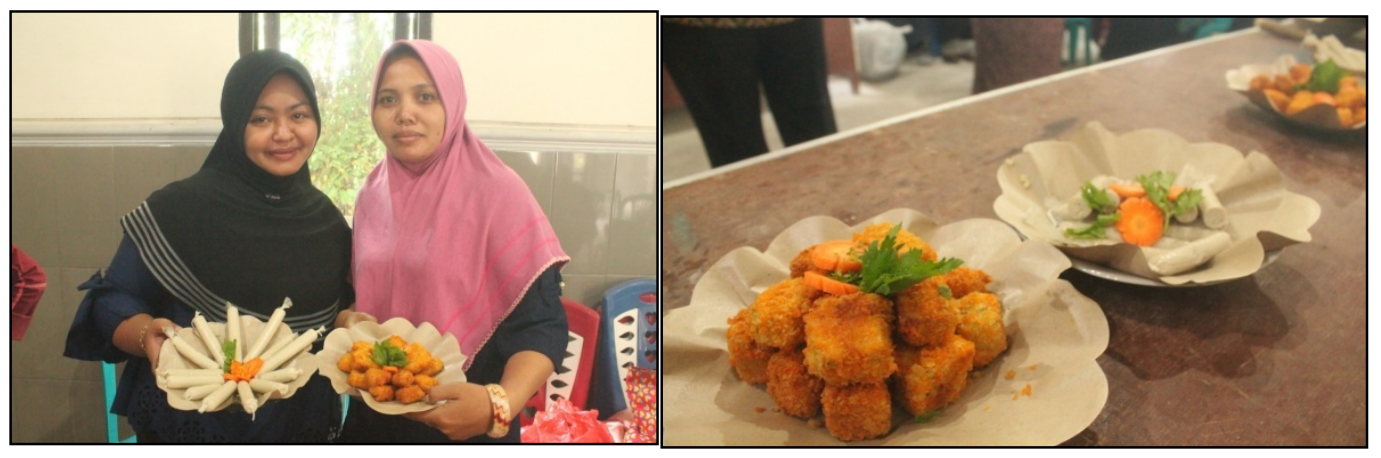

Gambar 6. Hasil Olahan Produk Ikan Bandeng: Sosis dan Nugget

\subsection{Kemampuan Ibu Ibu PKK Desa Pasi memasarkan produk nugget baik secara langsung (offline) maupun online}

Kemampuan Ibu Ibu PKK Desa Pasi untuk memasarkan produk dari olahan bandeng secara offline dan online telah berjalan dengan baik. Namun pada pemasaran secara online ibu ibu PKK Desa Pasi masih sedikit kesulitan karena minimnya jaringan internet yang ada pada desa Pasi.

\section{KESIMPULAN}

a. Sebagian besar ibu-ibu PKK di Desa Pasi tidak memiliki penghasilan dan hanya berperan sebagai Ibu Rumah Tangga. 
b. Kelompok Ibu Ibu PKK di Desa Pasi belum pernah mendapatkan pelatihan tentang kewirausaan maupun pengolahan tentang bahan pangan lokal sebelumnya.

c. Telah terbentuk kelompok usaha ibu-ibu PKK tambak "Pasi Berinovasi" sebagai wadah masyarakat untuk menjalankan usaha berbasis bahan pangan lokal.

d. Kegiatan Pengabdian Masyarakat dengan melakukan pelatihan penumbuhan jiwa kewirausahaan dan pembuatan bussines plan, pendampingan pembuatan produk dan pemasaran produk kepada Ibu-ibu PKK Desa Pasi dengan tujuan meningkatkan kesejehteraan istri petami tambak desa Pasi.

\section{UCAPAN TERIMA KASIH}

a. Kepala Balitbangda Kabupaten Lamongan

b. Bapak Suwaji, selaku Kepala Desa Pasi Kecamatan Glagah Kabupaten Lamongan

c. Ketua, Kepala L3M STIKes Delima Persada Gresik dan Dosen-Dosen Tim Pengabdian Masyarakat Desa Pasi Kecamatan Glagah Kabupaten Lamongan

\section{REFERENSI}

Badan Pusat Statistik (BPS) Kabupaten Lamongan. (2016). Kecamatan Glagah, Kantor Desa Pasi Dalam Angka 2016. Diunduh dari https://lamongankab.bps.go.id

Sulton. (2007). Manajemen Kewirausahaan Pendidikan. Malang: Universitas Negeri Malang.

Suprapto, A. (2007). Analisis tentang Memberdayakan Karyawan dengan Menanamkan Jiwa Entrepreneur. Jurnal Manajemen, Akuntansi dan Bisnis, Desember 2007

Thobias, Tungka, A.K., Rogahang, J.J. (2013). Pengaruh Modal Sosial terhadap Perilaku K ewirausahaan: Suatu Studi pada Pelaku Usaha Mikro Kecil Menengah di Kecamatan Kabaruan Kabupaten Talaud. Jurnal ActaDiurna, April 2013 